\title{
GÊNEROS DO UNIVERSO OFICIAL/EMPRESARIAL: PARA ALÉM DOS MANUAIS DE REDAÇÃO
}

GENERAL AND OFFICIAL UNIVERSE ON THE CORPORATE BUSINESS: BEYOND THE WRITING MANUAL PROCEDURES

\section{Erivaldo Pereira do Nascimento}

Doutorado em Letras pela Universidade Federal da Paraíba - UFPB erypn@hotmail.com 


\section{RESUMO}

O presente trabalho tem como objetivo discutir as contribuições dos estudos sobre a teoria dos Gêneros do Discurso de Bakhtin (2000 [1979]), para a descrição dos textos do universo empresarial/oficial. Trata-se de um trabalho descritivo e que aplica os critérios utilizados pelo autor para descrever os gêneros textuais/discursivos em dois gêneros formulaicos: $a$ ata $e \quad o$ memorando. Este trabalho está vinculado às investigações realizadas na Universidade Federal da Paraíba, através do projeto intitulado "Estudos Semântico-argumentativos de Gêneros do Discurso: Redação escolar e gêneros formulaicos (ESAGD)", financiado pelo CNPq, que tem como um dos seus principais objetivos investigar a argumentatividade presente em gêneros textuais do universo empresarial/oficial, tais como memorando, ata, ofício etc. Neste trabalho, mostraremos, a partir de investigações já realizadas e também em andamento, como é possível definir e descrever alguns gêneros do discurso, utilizando critérios linguístico-discursivos, sem ter de recorrer, exclusivamente, aos manuais de redação comercial/oficial.

Palavras-chave: Gêneros Textuais; Redação Comercial e Oficial; Argumentação. 


\section{ABSTRACT}

The present work aims to discuss the contributions of studies on the theory of Bakhtin Discourse Genre (2000 [1979]), to describe texts from the official/business universe. This is a descriptive work and it applies the criteria used by the author to describe the textual/discursive genres in two formulaic genres: the minute and the memo. This work is part of the investigations that are made at Federal University of Paraíba, through the project: "SemanticArgumentative Studies of the Discourse Genre: school composition and formulaic genres (ESAGD)", financed by CNPq, it has as one of its main objectives to investigate the argumentativity in textual genre of the official/business universe, such as memo, minute, letter etc. In this work, we demonstrate, from the previous and ongoing researches, how is possible to define and describe some discourse genre, through linguistic-discursive criteria, without having to see, exclusively, the manuals of commercial/official writing.

Key words: Textual Genre; Official and Business Writing; Argumentation. 


\section{INTRODUÇÃO}

O ensino de Língua Portuguesa e de produção de textos nos cursos de Secretariado Executivo tem sido pautado, na maioria das vezes, pelos manuais de redação oficial e comercial. Esses livros têm sido também, na maioria dos casos, a única fonte a que profissionais têm recorrido para orientar as suas produções textuais, no âmbito das instituições públicas e privadas.

Como todo manual, estão destinados a apresentar procedimentos técnicos, sobre como agir em determinadas situações. Nesse caso, estabelecem a maneira como os profissionais de escrita nas instituições públicas e privadas devem proceder ao elaborar os documentos e as comunicações, tais como atas, ofícios, memorandos, relatórios etc.

Considerando que os profissionais bacharéis em Secretariado Executivo muito mais do que repetir modelos e procedimentos, precisam ser profissionais empreendedores, proativos, reflexivos, capazes de analisar e de executar ações de cogestão, de assessoria e de consultoria nas instituições em que trabalham, parece um contrassenso a utilização de manuais técnicos que apresentam formulários, modelos e procedimentos muitas vezes distantes da realidade linguística e social dessas instituições.

É por essa razão que nos propomos, neste trabalho, a discutir a concepção de linguagem presente nos manuais de redação e apresentamos a possibilidade de se descrever os textos que circulam nas instituições públicas e privadas, a partir da concepção de gêneros textuais/discursivos, apresentada por Bakhtin (2000).

Inicialmente, discutiremos a concepção de língua que subjaz os manuais de redação, discutindo as implicações dessas concepções. Em seguida, apresentamos a Teoria dos Gêneros do Discurso ou Textuais, com base na Teoria de Bakhtin (2000), para depois mostrar, a partir dos estudos que realizamos sobre os gêneros formulaicos, como é possível descrever os textos do universo empresarial/oficial, com base nessa concepção.

Revista de Gestão e Secretariado, São Paulo, v. 1, n. 2, p. 123-142, jul./dez. 2010. 


\section{CONCEPÇÕES DE LÍNGUA E OS MANUAIS DE REDAÇÃO}

É preciso compreender a concepção de língua que norteia os manuais de redação oficial/empresarial, para melhor entender os limites de sua aplicação, nas instituições. Somente uma compreensão clara da concepção de língua e interação que subjaz esses manuais, podem nos fazer refletir sobre sua utilização pelos profissionais de Secretariado Executivo.

Koch e Elias (2002, p.9) apresentam as três principais concepções de língua e texto que permeiam os estudos de linguagem, bem como sua aplicação. A primeira é a noção de "língua como representação do pensamento". Para essa concepção, a língua serve como um instrumento que representa aquilo que o sujeito pensa e quer transmitir. Nessa perspectiva, o texto é visto como um produto do pensamento do seu autor.

A segunda concepção é aquela que apresenta a língua como estrutura, ou como código. Para essa visão, a língua é um instrumento do qual nos valemos para transmitir nossas mensagens para alguém. Aqui "o texto é visto como simples produto da codificação de um emissor a ser decodificado pelo leitor/ouvinte, bastando a este, para tanto, o conhecimento do código utilizado" (KOCH; ELIAS, 2002, p.10).

A terceira concepção, denominada por Koch e Elias de interacional ou dialógica, é aquela que apresenta a língua a partir do seu uso, por sujeitos que são ativos, constroem-se e interagem socialmente pela linguagem. A concepção interacional considera a língua como "o próprio lugar da interação e da constituição dos interlocutores" (KOCH; ELIAS, idem ibidem).

Para essa perspectiva, o texto não é um produto acabado; ele é construído na interação e, por essa razão, é uma atividade complexa de produção de sentidos. Da mesma maneira, os sujeitos que usam a linguagem - aqui não mais denominados de emissor e receptor, mas de interlocutores - são sempre ativos e se utilizam de uma imensa variedade de saberes, entre os quais os de natureza puramente linguística, no processo de construção de textos.

O problema das duas primeiras concepções de língua é que elas desconsideram $o$ uso linguístico e, por conseguinte, o fato de que a língua apresenta variedades. A língua não é uma estrutura fechada, tampouco se pode falar em formas linguísticas únicas e perfeitas, ideais para o uso.

Revista de Gestão e Secretariado, São Paulo, v. 1, n. 2, p. 123-142, jul./dez. 2010. 
Em suas situações de uso diário, os interlocutores utilizam-se da língua para diferentes ações sociais e, de acordo com suas intenções e suas próprias concepções de mundo e de vida, representam-se na língua, modificam-na e a (re)constroem. Da mesma maneira como não existe uma forma única, não existe uma forma perfeita, ideal. O que existe, na verdade, é a forma adequada às intenções dos interlocutores, sejam elas quais forem.

Desconhecendo a realidade de uso da linguagem, os manuais de redação baseiam-se numa concepção normativa ou estruturalista de linguagem, apresentando modelos ideais de estruturas, de documentos e de textos. Medeiros (2006, p. 57) afirma que "a língua é um código que possibilita a comunicação", acrescentando ainda que se trata de "um sistema de signos e combinações; um sistema de sons, de caráter abstrato, utilizado na fala". O mesmo autor ainda chega a afirmar que a linguagem é "o meio que se utiliza para exprimir ideias, desejos, sentimentos".

O manual de Medeiros ainda faz uma distinção entre as modalidades escrita e falada, permeada por uma concepção de língua escrita ideal, em que coloca a língua falada como um modelo inferior de linguagem, já que a escrita é apresentada como "presa às regras da gramática e ao padrão considerado culto da língua" (MEDEIROS, 2006, p.58).

Essa concepção, às vezes de maneira implícita, é perceptível em outros manuais de redação, inclusive nos manuais oficiais dos órgãos públicos. Os manuais, tanto os oficiais como os publicados sob a forma de livro, oferecem modelos de documentos, cujo fim não é nada mais do que criar padrões de interação.

Nos manuais oficiais ainda se prega uma tentativa de objetividade e de impessoalidade, tentando reduzir a linguagem a um fim único: o interesse dos cidadãos. É isso, por exemplo, o que encontramos no manual de redação da Câmara dos Deputados (p. 32):

Em outras palavras, a redação oficial é elaborada sempre em nome do serviço público e sempre em atendimento ao interesse geral dos cidadãos. Sendo assim, é inconcebível que os assuntos objeto dos expedientes oficiais sejam tratados de outra forma que não a estritamente impessoal.

Revista de Gestão e Secretariado, São Paulo, v. 1, n. 2, p. 123-142, jul./dez. 2010. 
A tentativa de impessoalidade pregada pelos manuais, bem como a padronização dos documentos, não somente distancia a língua das interações reais dos sujeitos, no próprio âmbito das organizações, como apresenta uma visão reducionista da própria linguagem.

A impessoalidade, afirma Ducrot (1988, p.17), é uma estratégia argumentativa que pretende isentar de responsabilidades o locutor ou, ainda, escondê-lo por trás da máscara da imparcialidade. Em outras palavras, é apenas uma estratégia argumentativa, entre tantas outras, presente nos gêneros textuais do universo oficial.

Da mesma forma, não se pode falar em uma língua descritiva nem ideal, pois, como também afirma Ducrot (1988, p.50), se a língua descreve a realidade é através dos aspectos subjetivos ou intersubjetivos, ou seja, se há algo descritivo e objetivo na língua é em função da nossa expressividade (subjetividade) e das intenções que temos, quando interagimos como outros sujeitos (intersubjetividade).

Por essa razão, pode-se falar que a concepção de língua e o princípio de objetividade que fundamentam os manuais de redação, além de não se sustentarem mais teoricamente, não trazem resultados eficazes nem para a análise da linguagem no universo do Secretariado, tampouco para o próprio uso, uma vez que mascara a própria realidade linguístico-discursiva desse universo.

Fornecer modelos de documentos, padronização baseada em formas de cortesia, espaçamento, nível de vocabulário permitido etc. não garante que os secretários consigam produzir textos com eficiência. A textualidade não se constrói apenas com esses elementos: isso é muito pouco para se produzir um bom texto, adequado às intenções do sujeito no uso real da linguagem.

Além disso, convém ressaltar que a existência desses padrões sequer garante que os interlocutores os utilizem e, se o utilizarem, o façam da maneira como é posto nos manuais. De acordo com suas intenções, os sujeitos podem muito bem modificar os padrões, adaptá-los, ou até ignorá-los.

Por essa razão, faz-se necessária a investigação linguística nesse ramo de produção social. Muito mais do que fornecer modelos, a Linguística irá explicar a maneira como, realmente, os sujeitos utilizam a língua nesse contexto, de que gêneros de textos se valem e como se portam ao utilizá-los. Além disso, trará a possibilidade de enxergamos a língua não apenas como estrutura, mas,

Revista de Gestão e Secretariado, São Paulo, v. 1, n. 2, p. 123-142, jul./dez. 2010. 
principalmente, como o lugar social da interação, permeada por nossas intenções, crenças, valores e posicionamentos.

\section{A TEORIA DOS GÊNEROS TEXTUAIS E/OU DISCURSIVOS}

De maneira geral, a nomenclatura gêneros textuais e/ou discursivos é utilizada para se referir aos textos que utilizamos diariamente, nos mais diversos grupos sociais, quando interagimos. São exemplos desses gêneros os mais diversos textos orais e escritos, formais ou informais: conversa, telefonema, carta, ofício, petição, aula expositiva, notícia, romance etc.

Um dos primeiros estudiosos a se preocupar em teorizar sobre esses textos, a partir de uma concepção de língua em uso, foi Bakhtin, que os denominou de gêneros do discurso.

Qualquer enunciado considerado isoladamente, é claro, individual, mas cada esfera de utilização da língua elabora seus tipos relativamente estáveis de enunciados, sendo isso que denominamos gêneros do discurso. (grifo do autor). (BAKHTIN, 2000[1979], p. 279)

Bakhtin justifica a relativa estabilidade como característica intrínseca dos gêneros textuais/discursivos, pelo próprio caráter sócio-histórico dos gêneros. 0 estudioso afirma que cada esfera da atividade humana "comporta um repertório de gêneros do discurso que vai diferenciando-se e ampliando-se à medida que a própria esfera se desenvolve e fica mais complexa" (idem, p.279). Essa posição do autor estabelece uma relação muito direta entre os processos de formação dos gêneros e as ações humanas. De acordo com Marcuschi (2000, p. 24), Bakhtin aproxima a língua à vida humana de tal maneira que uma penetra na outra e, quando alguém escolhe um gênero, nunca o fará como um fato individual, mas coletivo, pois o gênero é uma forma de inserção social e de execução de um plano comunicativo intencional.

Marcuschi, por sua vez, também considera os gêneros textuais/discursivos a partir de uma concepção de língua em uso. Para esse autor, os gêneros 
textuais "são entidades sócio-discursivas e formas de ação social incontornáveis em qualquer situação comunicativa" (2002, p.19).

A variedade dos gêneros pressupõe, segundo Bakhtin, a variedade de intenções da pessoa que fala ou escreve. Dessa maneira, o autor insiste na diversidade dos fatos sociais realizados pelos mais diversos grupos e, consequentemente, nos fatos de linguagem. Portanto, como dependem da intenção e dos fatos sociais, os gêneros do discurso são infinitos e heterogêneos (Bakhtin, 2000, p. 279).

E esses gêneros, conforme sua complexidade e esfera de uso, foram sistematizados por Bakhtin em dois grandes grupos: gêneros primários (simples) e gêneros secundários (complexos). Os primários são aqueles da vida cotidiana e mantêm uma relação imediata com as situações nas quais são produzidos. Os gêneros secundários, por sua vez, aparecem nas circunstâncias de uma situação cultural mais complexa e relativamente mais desenvolvida. Nesse segundo grupo, estariam, portanto, os gêneros produzidos nos âmbitos das instituições públicas e privadas.

A classificação dos gêneros do discurso ainda não é um problema resolvido pela Linguística. A própria denominação como gêneros do discurso não é unanimidade, pois coexistem termos como gêneros discursivos e gêneros textuais. Embora existam razões teóricas para a existência de diferentes nomenclaturas, tomamos aqui um termo pelo outro, dados os objetivos do presente trabalho e considerando que as definições tratam do mesmo objeto.

Depois de Bakhtin (2000[1979]), vários estudiosos propuseram diferentes classificações para os gêneros do discurso. Entre eles, Beaugrande (1980), Van Dijk (1985), Adam (1993) e o próprio Marcuschi (2000). As diferentes classificações são baseadas em diferentes critérios e adotam diferentes perspectivas teóricas.

No entanto, foi Bakhtin quem estabeleceu os critérios básicos para definir qualquer gênero textual/discursivo. Além de considerar sua função sociocomunicativa, ou seja, em que circunstância e com que intenções são produzidos determinados gêneros, a descrição de um gênero há de considerar, segundo o estudioso (2000, p. 279), três aspectos: conteúdo temático, estilo verbal e construção composicional.

Revista de Gestão e Secretariado, São Paulo, v. 1, n. 2, p. 123-142, jul./dez. 2010. 
a) O conteúdo temático diz respeito ao tipo de informação, o objeto do dizer, de que geralmente são compostos os gêneros textuais. Em outras palavras, isso significa que cada gênero textual é utilizado para veicular determinados conteúdos e o tratamento dado a esse conteúdo vai depender não só do próprio gênero, mas da intenção de quem o produz.

Bakhtin (2000, p. 301) afirma que "o querer-dizer do locutor se realiza acima de tudo na escolha de um gênero do discurso". Isso significa que dependendo do assunto que vamos tratar - com quem vamos tratar e das nossas intenções ao tratá-lo - determinam, de certa forma, que gênero vamos utilizar. Isso é fácil de ser percebido, no âmbito das instituições. Não utilizamos uma ata para tratar das mesmas informações que tratamos em um relatório ou em um edital. Dependendo do assunto, da intenção que tenha e a quem me dirija, eu escolho um ou outro gênero.

b) O estilo verbal diz respeito aos recursos da língua - recursos lexicais, fraseológicos e gramaticais, como aponta Bakhtin (2000, p. 179), com que se compõe cada um dos gêneros textuais. Afirma ainda o autor que "o estilo linguístico ou funcional nada mais é senão o estilo de um gênero peculiar a uma dada esfera da atividade e da comunicação humana" (p. 283).

Assim, com base em Bakhtin, pode-se afirmar que o estilo verbal de uma ata não é necessariamente o mesmo estilo verbal de um memorando ou de um ofício. Por servirem a propósitos comunicativos diferentes, o vocabulário, as expressões linguísticas, o nível de formalidade, a coordenação de frases e sentenças, tudo isso vai ser diferenciado de um gênero para outro.

Discutindo, por exemplo, os gêneros do universo oficial, Bakhtin (2000, p. 283) diz que é próprio dos gêneros desse universo a forma padronizada e a tentativa de desfavorecer a individualidade. Afirma o autor que "nesses gêneros só podem refletir-se os aspectos superficiais, quase biológicos, da individualidade". No entanto, nas investigações realizadas através do projeto ESAGD temos percebido que, apesar dessa tentativa de desfavorecer a individualidade é possível perceber a marca do locutor (responsável pelo discurso) nos gêneros padronizados ou formulaicos.

Estratégias de modalização, da polifonia, da utilização de operadores argumentativos, entre outros recursos linguístico-discursivos, têm sido

Revista de Gestão e Secretariado, São Paulo, v. 1, n. 2, p. 123-142, jul./dez. 2010. 
detectadas como marcas de argumentatividade nos textos e essas marcas, bem como seu uso, variam de um gênero para outro.

c) A estrutura composicional, o último critério apontado por Bakhtin, diz respeito à forma de um determinado gênero do discurso. Afirma Bakhtin (2000, p.301) que "o intuito discursivo do locutor, sem que este renuncie à sua individualidade e à sua subjetividade, adapta-se e ajusta-se ao gênero escolhido, compõe-se e desenvolve-se na forma do gênero determinado". O autor ainda afirma que todos os nossos textos "dispõem de uma forma padrão e relativamente estável de estruturação de um todo".

É exatamente pelos textos possuírem uma forma padrão que somos capazes de identificar que um determinado texto pertence a um determinado gênero e prever as intenções de quem o produziu, como explica o próprio estudioso. Se pensarmos no universo empresarial, pela forma mesmo, já somos capazes de prever que um dado documento se trata de um edital, memorando ou ata, por exemplo. Também pela forma, já criamos uma determinada expectativa de que tipo de assunto tratará e de que prováveis intenções podem estar expressas no texto. Isso ocorre porque "as formas da língua e as formas típicas de enunciados, isto é, os gêneros do discurso, introduzem-se em nossa experiência e em nossa consciência conjuntamente e sem que sua estreita correlação seja interrompida" (BAKHTIN, 2000, p. 301).

Os estudos a respeito dos gêneros textuais e/ou discursivos são de fundamental importância para a área do Secretariado porque permitirá a descrição dos diferentes textos que circulam no universo das instituições públicas e privadas. Estudos descritivos que mostrem como se estruturam, se organizam e funcionam discursivamente os diferentes gêneros são relevantes por si só, uma vez que dará um tratamento mais científico e menos normativo ao funcionamento desses textos. Esses estudos podem muito bem servir de base para que se derrubem preconceitos a respeito dos documentos produzidos no âmbito das instituições, muitas vezes colocados em segundo plano nas investigações linguísticas.

Também servirão para que possamos conhecer como realmente funcionam e se estruturam os textos, fugindo de fórmulas prontas. Esses estudos, muito mais do que questionar manuais ultrapassados, permitirão a elaboração de

Revista de Gestão e Secretariado, São Paulo, v. 1, n. 2, p. 123-142, jul./dez. 2010. 
novos materiais que considerem o uso real dos textos que circulam no universo das instituições oficiais e privadas.

\section{APLICANDO OS CRITÉRIOS DE BAKHTIN EM GÊNEROS FORMULAICOS}

A partir de investigações realizadas no LASPRAT (Laboratório SemânticoPragmático de Textos), Campus I, e no LAEL (Laboratório de Estudos Linguísticos), Campus IV, da UFPB, pelo projeto ESAGD, apresentamos, a seguir, de que maneira temos aplicado os critérios propostos por Bakhtin para definir e diferenciar os gêneros do discurso com os quais trabalhamos.

Obviamente que o que vamos apresentar a seguir não exaure o tema em questão, uma vez que nosso objetivo, no referido projeto, não é descrever cada um dos gêneros em sua totalidade. Nossas investigações têm sido mais especificamente no sentido de descrever a estrutura semântico-argumentativa dos gêneros em investigação. No entanto, como não há trabalhos significativos que tratem dos gêneros formulaicos do universo empresarial/oficial em uma perspectiva mais discursiva ou interacional, deparamo-nos com a necessidade de definir os gêneros, apresentar alguma caracterização macro de cada gênero, a fim de tratarmos do nosso objeto específico: a descrição semântica.

O que apresentamos a seguir é, portanto, um primeiro passo para se começar a pensar uma descrição desses textos do universo empresarial/oficial, a partir de uma concepção de gêneros do discurso.

Trabalharemos aqui com dois gêneros: a ata e o memorando. O último já foi objeto de descrição e o primeiro está em investigação, na sua fase final. Para ambos os gêneros aplicaremos os três critérios definidos por Bakhtin e utilizaremos dados de nossas pesquisas a respeito da argumentatividade nesses gêneros.

4.1 ATA

Tratando especificamente da ata, podemos afirmar que ela é um tipo de documento de suma importância para as organizações, tanto na administração pública, quanto na área privada. É usado como um meio de comunicação

Revista de Gestão e Secretariado, São Paulo, v. 1, n. 2, p. 123-142, jul./dez. 2010. 
altamente formal, cuja finalidade é relatar todos os assuntos tratados em uma reunião, assembleia ou convenção. Daí as suas várias espécies: ata de assembleia geral extraordinária, de assembleia geral ordinária etc. A ata é, portanto, um relatório "pormenorizado" de tudo o que se passou em uma reunião, assembleia ou convenção.

Conteúdo - Aplicando os três critérios de Bakhtin ao gênero ata, é possível identificar elementos significativos para uma descrição mais apropriada desse gênero. Com relação ao conteúdo, a ata pode apresentar os mais variados tipos de assuntos, como esclarecimentos, discussões, tomada de decisão, entre outros, comuns a reuniões e a seções.

Segundo Bakhtin (2000, p. 300), é no conteúdo temático que se poderá perceber a maneira como o autor trata o tema abordado: esse pode ser apresentado de forma mais ou menos exaustivo. No caso da ata, esse conteúdo é apresentado com uma forma relativamente exaustiva, uma vez que todos os detalhes e os discursos da reunião não são transcritos em sua íntegra, mas sumarizados por quem o produz. Em outras palavras, é necessário transpor os discursos, sintetizando-os e relatar, principalmente, as decisões tomadas por ocasião da reunião ou da seção relatada. Cabe a quem redige a ata, portanto, a decisão de fazer os recortes dos depoimentos, selecionando o que julga mais importante.

Exatamente porque os conteúdos (ações, depoimentos, relatos e decisões) são simplificados e sintetizados é que se faz necessária a apreciação. Se os relatos fossem apresentados na íntegra e não houvesse a necessidade de sintetizá-los, provavelmente não haveria a necessidade de aprovar o que foi relatado.

Estilo - Bakhtin (2000) postula que o estilo de um gênero pode ser reconhecido através da forma linguística e funcional, referindo-se à forma peculiar que cada gênero assume em cada esfera da atividade e da comunicação humana, na qual se torna relativamente estável do ponto de vista temático composicional e estilístico. No caso da ata, é possível afirmar que a marca da polifonia é própria do estilo composicional desse gênero textual, assim como a presença de elementos modalizadores.

Revista de Gestão e Secretariado, São Paulo, v. 1, n. 2, p. 123-142, jul./dez. 2010. 
O estilo polifônico, ou seja, a presença de diferentes relatos ao longo do texto, é algo inerente ao gênero, uma vez que a ata serve exatamente para esse fim (NASCIMENTO; OLIVEIRA, 2010). As nossas investigações no LASPRAT e no LAEL têm apontado que a presença da polifonia de locutores, em que o locutor responsável pela ata (aquele que a assina) traz para seu texto a presença de outros locutores (quais sejam os discursos atribuídos a membros de uma reunião ou seção) através do estilo direto ou indireto, das aspas de diferenciação e da presença de verbos dicendi (dizer, afirmar, falar etc.).

Ainda com relação aos verbos dicendi, que introduzem relatos, conseguimos perceber que esses são índices de argumentatividade, uma vez que funcionam como elementos modalizadores. Assim, verbos como afirmar, sugerir etc. têm sido utilizados pelo locutor da ata para introduzir o relato de outros locutores e deixar registrada uma avaliação, um julgamento com relação ao discurso relatado, determinando como o relato deve ser lido. Convém assinalar que a modalização é um fenômeno linguístico-discursivo que permite a um locutor, responsável por um enunciado, imprimir uma avaliação em seu enunciado, ou na própria enunciação (tomada em sentido amplo), em função de seus interesses e da interlocução. (NASCIMENTO, 2009).

Outros elementos do estilo da ata é a presença da terceira pessoa do singular, no entanto, no corpus que investigamos chegamos a encontrar relatos em primeira pessoa, sobretudo quando o texto é produzido não por secretários, mas por membros da própria seção, designados para tal. No entanto, como esse fenômeno aparece em casos isolados, não é possível afirmar que a primeira pessoa é marca do estilo do gênero. O corpus tem demonstrado que a presença de terceira pessoa, numa tentativa de criar e manter a marca da imparcialidade, é marca do estilo do gênero.

Construção Composicional - Quanto à construção composicional, as características mais comuns na estrutura do gênero ata, apontadas em diversos manuais de redação, são: título, data, local, convocação prévia que determina a reunião, finalidade da reunião, ordem do dia, fecho e assinaturas.

De acordo com Sabino e Rocha (2004, p. 63) a ata costuma ser um texto compacto, a transcrição pode ser feita à mão ou digitada e impressa. A forma de ata informatizada exige uma organização, pois as folhas impressas e assinadas

Revista de Gestão e Secretariado, São Paulo, v. 1, n. 2, p. 123-142, jul./dez. 2010. 
serão arquivadas na empresa para posterior encadernação; já a ata feita à mão, geralmente, é registrada em um livro especial, devendo-se tomar todas as precauções ao redigi-las, para resguardar o texto contra possíveis fraudes. Caso haja extravio de folhas, invalidará o livro: "Das reuniões da seção, serão lavradas as atas, paginadas em sequência ininterrupta e, sendo aprovadas, receberão as assinaturas de todos os membros presentes." A ata de uma reunião será lida e aprovada na reunião seguinte, afirmam os autores.

De acordo com os manuais de redação, as partes de uma ata variam segundo a natureza das reuniões cujos eventos se registram. Entretanto, as mais importantes e que mais frequentemente aparecem, são as seguintes: título, local e data, finalidade da reunião, ordem do dia, fecho e assinaturas. Uma de suas particularidades é que a ata deve ser assinada em alguns casos pelos participantes da reunião, e sempre, pelo presidente ou secretário, como afirma Medeiros (2006).

\subsection{MEMORANDO}

O memorando é um tipo de documento usual nas relações internas das empresas, instituições ou órgãos públicos. Tem por finalidade estabelecer a comunicação entre funcionários, que podem estar hierarquicamente em mesmo nível ou em nível diferente, de diversas unidades administrativas, setores ou departamentos de uma mesma organização.

Conteúdo - No que se refere ao conteúdo, as nossas pesquisas têm demonstrado que o memorando é um documento utilizado para tratar de assuntos de caráter rotineiro ao âmbito interno das instituições: fazer solicitações, noticiar eventos, informar, divulgar, transformar ordens, instruções e decisões administrativas, marcar datas, entre outros (NASCIMENTO, GONÇALVES, 2010).

Segundo Beltrão e Beltrão (2005, p. 262), o memorando é um dos documentos mais frequentes em qualquer empresa: "O memorando, sempre escrito em papel no formato meio-ofício, destinava-se inicialmente a tratar de parte de assunto focado em mensagem anterior, passando depois a ser para veicular mensagens menos solenes e de poucas palavras $[\ldots]^{\prime \prime}$. 
Por tratar de assuntos rotineiros, a contextualização muitas vezes é desnecessária e o assunto não precisa ser tratado exaustivamente. Por essa razão, o nível de informatividade é baixo, ou seja, não se apresenta no texto do memorando uma grande quantidade de informações, nem essas são exaustivamente aprofundadas.

Estilo - Por ter circulação limitada ao âmbito interno das organizações, dispensa formalidades excessivas, diferentemente dos documentos que veiculam informações externas, como o oficio e a carta comercial. Por essa razão, uma das características desse documento, e isso se aplica tanto no serviço público como no privado, é ter como objetivo a rapidez e a simplicidade na comunicação de suas mensagens, que devem ser escritas de forma clara, breve e direta.

Talvez em função dessa clareza, o vocabulário seja mais simples e a terceira pessoa do singular predomine. No entanto, mesmo com a pretensa clareza e objetividade, nossas pesquisas têm demonstrado que a argumentatividade se faz presente nesse gênero através de modalizadores discursivos e operadores argumentativos.

Em uma investigação com 20 memorandos produzidos por uma instituição de ensino superior e um órgão das Forças Armadas, detectamos que a presença de modalizadores do tipo deôntico (como dever, é obrigatório que, é necessário etc.) são frequentes em textos produzidos por setores ou segmentos da hierarquia superior das instituições para setores ou segmentos a eles subordinados. No entanto, quando se trata do inverso, modalizadores do tipo epistêmico-quase asseverativos (como é possível, poderia etc.) são frequentemente utilizados (NASCIMENTO; GONÇALVES, 2010).

Além da modalização, outros elementos linguísticos relativamente presentes nos memorandos são os operadores argumentativos. Os operadores argumentativos são elementos da língua que, ao serem utilizados em um texto, apresentam determinados pontos de vista ou apontam para determinadas conclusões (Ducrot, 1988). Expressões como a fim de, porque, em razão de etc. são operadores utilizados nos memorandos para apresentar finalidades, justificativas e outras relações de sentido, com o objetivo de dar determinados direcionamentos ao longo do texto. Esses elementos além de realizarem a tessitura textual (conectarem enunciados, porções textuais) servem para

Revista de Gestão e Secretariado, São Paulo, v. 1, n. 2, p. 123-142, jul./dez. 2010. 
direcionar o leitor para determinadas conclusões pretendidas pelo locutor do texto e são bastante eficazes.

A investigação que realizamos revela que, uma vez que o memorando trata de conteúdos de maneira menos exaustiva e possui um estilo menos formal que outros documentos do universo empresarial/oficial, a utilização de elementos semântico-discursivos que geram um efeito argumentativo mais imediato e direto, a exemplo dos modalizadores e dos operadores argumentativos, faz-se presente. Comprova também que há argumentatividade no gênero, apesar da pretensa objetividade (NASCIMENTO; GONÇALVES, 2010).

Construção Composicional - No que se refere à estrutura composicional do memorando, os próprios manuais de redação nos fornecem dados suficientes para a descrição do gênero. Por ter circulação limitada ao âmbito interno das organizações, dispensa formalidades excessivas na sua estrutura, diferentemente dos documentos que veiculam informações externas, como o oficio e a carta comercial. Geralmente as empresas privadas optam pela padronização, com a criação de formulários que servem de amostra para digitação do documento, visando à praticidade e à rapidez.

Já as empresas públicas seguem o formato estabelecido pela Instrução Normativa, no 4, de 6-3-1992. "São partes constitutivas do memorando: timbre, endereço (quando se trata de empresa privada), código (iniciais do departamento), número do memorando, localidade, ementa (referência) ou assunto, receptor, texto, assinatura, anexos". (MEDEIROS, 2006, p.231).

Quanto a seu formato, segue o modelo padrão ofício, exceto no que diz respeito ao destinatário. Este deve ser mencionado pelo cargo que ocupa. De acordo com Beltrão e Beltrão (2005), não se deve usar folha de continuação; e se houver fecho, só será necessário o uso de fórmulas de cortesia quando o memorando for dirigido para matrizes ou filiais da organização.

No entanto, em nossas investigações, também constatamos a presença de fórmulas de cortesias em memorandos para órgãos internos. Tem sido comum a utilização de vocativos, seguidos ou não de fórmulas de cortesias, tais como: Prezado Senhor, Senhor, Senhor Diretor, Senhor Dirigente, Magnífico Reitor, Ilm. ${ }^{\circ}$ Sr. etc. No que refere às fórmulas de desfecho, mesmo para setores próximos, encontramos expressões como Cordialmente, Respeitosamente e

Revista de Gestão e Secretariado, São Paulo, v. 1, n. 2, p. 123-142, jul./dez. 2010. 
Atenciosamente. (NASCIMENTO; GONÇALVES, 2010). Isso demonstra que nem sempre o que os manuais pregam é o que acontece no âmbito das instituições e que, dependendo dos interesses dos locutores, esses elementos da estrutura composicional podem ser (e são) alterados.

\section{CONSIDERAÇÕES FINAIS}

Conforme observamos acima, a aplicação dos três critérios de Bakhtin permite uma melhor descrição e definição dos gêneros textuais. Isso ocorre porque esses critérios permitem enxergar além dos formulários e dar conta do texto em sua totalidade, percebendo como a função sociocomunicativa dos gêneros se materializa no tratamento dado ao conteúdo, ao estilo linguístico e à estrutura composicional.

No que se refere à ata, percebe-se que a sua função de relatar justifica a presença da polifonia e da modalização, o tratamento relativamente exaustivo do objeto (conteúdo), bem como a presença de elementos referenciais ou delimitadores (tais como local, data, pessoas presentes na seção etc.).

No memorando, como tem a função estabelecer comunicação entre órgãos de uma mesma instituição, o objeto não é tratado exaustivamente (a simplificação do conteúdo é o padrão), a linguagem não é tão formal, mas é explicitamente argumentativa (através de modalizadores e operadores argumentativos) e a sua estrutura composicional é marcada pela presença de elementos referenciais (data, setores, pessoas envolvidas), fórmulas de cortesia, desfecho etc., próprios da correspondência.

Considerando que a aplicabilidade acima realizada permite enxergar melhor os textos e se desvencilhar de critérios puramente normativos, a utilização da proposta de Bakhtin parece-nos mais eficaz e produtiva do que a que apresenta os manuais de redação, uma vez que a proposta bakhtiniana trata o texto na sua totalidade.

Aplicando os critérios acima utilizados é possível ir além dos padrões e formulários e enxergar como se materializam os textos, no que se refere ao seu conteúdo e à forma de dizer esse conteúdo. Para o profissional de Secretariado e para todos os outros profissionais que lidam com a documentação, no âmbito 
das instituições públicas e privadas, isso é muito mais do que uma sugestão, é imperativo.

Como produtor diário de texto, o secretário não deve ser apenas uma pessoa capaz de preencher formulário, mas deve tornar-se um profissional de linguagem, capaz de, dentro de formulários ou não, utilizar a língua de maneira eficaz, a fim de atingir determinadas intenções (verbais ou não).

Por isso não basta conhecer a estrutura composicional dos textos (as fórmulas de cortesia adequada, onde colocar local e data etc.). É necessário saber escolher o que dizer (conteúdo) e como dizer (estilo linguístico), a fim de atingir os propósitos comunicativos. E como afirma Bakhtin e outros estudiosos da linguagem, escolher o que dizer e como dizer implica a escolha de um gênero textual, com suas características e funções próprias. Daí a necessidade de conhecer cada um desses gêneros em sua totalidade.

Convém ainda assinalar que essa proposta não diz como os textos devem ser, mas descreve-os e explica como eles são. Por essa razão, pode ser utilizada para que os profissionais da escrita entendam como se materializam os textos e, a partir daí, tornem-se competentes, linguisticamente falando, para produzir, reproduzir e transformar e transpor novos textos.

\section{REFERÊNCIAS}

BAKHTIN, Mikhail. Estética da criação verbal. Tradução M.E.G. Gomes. 3 a edição. São Paulo: Martins Fontes, 2000 [1979].

BELTRÃO, Odacir; BELTRÃO, Mariúsa. Correspondência: linguagem \& comunicação: oficial, comercial, bancária, particular. 23 ed. rev. e atual. São Paulo: Atlas, 2005.

DUCROT, Oswald. Polifonia y argumentación: Conferencias del Seminario Teoría de la Argumentación y Análisis del Discurso. Cali: Universidad del Valle, 1988.

$\mathrm{KOCH}$, Ingedore Villaça; ELIAS, Vanda Maria. Ler e aprender: os sentidos do texto. São Paulo: Contexto, 2006.

MANUAL DE REDAÇÃO da Câmara dos Deputados. s/d. Brasília-DF (mimeo).

Revista de Gestão e Secretariado, São Paulo, v. 1, n. 2, p. 123-142, jul./dez. 2010. 
MARCUSCHI, Luiz Antônio. Gêneros Textuais: o que são e como se classificam. Recife: Universidade Federal de Pernambuco, 2000. (mimeo)

- Gêneros textuais: definição e funcionalidade. In: DIONÍSIO, Ângela Paiva et al (org.). Gêneros textuais e ensino. Rio de Janeiro: Lucerna, 2002.

MEDEIROS, João Bosco. Correspondência: técnicas de comunicação criativa. 18a edição. São Paulo: Atlas, 2006.

NASCIMENTO, Erivaldo Pereira do. Jogando com as vozes do outro: A polifonia recurso modalizador na notícia jornalística. João Pessoa, Universidade Federal da Paraíba, 2005 (tese de doutorado).

- A modalização como estratégia argumentativa: da proposição ao texto. IN: Anais do VI Congresso Internacional da Abralin. João Pessoa: Editora Idéia, 2009. pp. 1369 a 1376 (cd room).

NASCIMENTO, Erivaldo P. do; GONÇALVES, Kátia Regina de Almeida. A modalização como estratégia semântico-argumentativa no gênero textual/discursivo Memorando. João Pessoa: UFPB, 2010 (mimeo).

NASCIMENTO, Erivaldo P. do; OLIVEIRA, Pricila Rafaela dos S. Argumentação na redação oficial/comercial: a polifonia no gênero ata. João Pessoa: UFPB, 2010 (mimeo).

SABINO, Rosimeri F.; ROCHA, Fabio G. Secretariado: do escriba ao web writer. Rio de Janeiro: Brasport, 2004.

Revista de Gestão e Secretariado, São Paulo, v. 1, n. 2, p. 123-142, jul./dez. 2010. 